\title{
Application of Project Progress Management Based on Building Information Modeling
}

\author{
Jixue Zou * \\ College of human settlements \\ $\mathrm{Xi}$ 'an Eurasia university \\ $\mathrm{Xi}$ 'an, Shaanxi, China \\ 894912195@qq.com
}

\author{
Haoqiang Wang \\ College of human settlements \\ $\mathrm{Xi}$ 'an Eurasia university \\ Xi 'an, Shaanxi, China \\ 1501972759@qq.com
}

\author{
Yu Lei \\ College of human settlements \\ $\mathrm{Xi}$ 'an Eurasia university \\ Xi 'an, Shaanxi, China \\ 894912195@qq.com
}

\begin{abstract}
Project schedule management is a significant link in the process of project construction. Because of the low efficiency of traditional project schedule management, it brings great loss to the national economy and social investment. Therefore, it is imperative to find a more effective project schedule management method. The emergence of building information model greatly facilitates the construction and improves the construction efficiency, but its application in the management stage is less. So how to improve the application level of the management stage has become the top priority. This paper analyzes the utility of building information modeling in the management stage and the advantages of popularizing building information modeling from a unique perspective.
\end{abstract}

Keywords-Building management; efficient

Information Modeling; Progress

\section{INTRODUCTION}

With the booming development of China's economy in recent years, people's living standards have been remarkably improved, and people's demands on buildings are also raised, more and more people demand that buildings meet their basic requirements as well as their needs in terms of appearance, longevity and other aspects [1]. As a result, the scale of construction projects is getting larger and larger, and the difficulty is also increasing, and the traditional project management mode has been reveled somewhat inadequate. Therefore, as far as the construction industry, how to improve the level of project management through effective means has become the key problem. For project management, a reasonable and effective project management method can make the overall effect of project construction reach the optimal. However, controlling time limit, cost manpower and improving project quality seem to be beyond the traditional management mode. In recent years, a new management tool has become a hot topic in the industry. Building information modeling, as a new method, concludes all project information from the design to the end of the life cycle of the project. In different production stages, this tool can be used to timely share and transmit information to project construction personnel, so as to provide a basis for collaborative work of all participants in project construction, improve production efficiency, reduce construction waste and save construction cost. However, this tool has achieved little in the construction management stage, and how to apply this technology into project schedule management has troubled many people. On this basis, this article explains how to better apply Building Information Modeling in project schedule management.

\section{Status of Project Progress Management}

The traditional project schedule management is based on CAD drawings, but it needs to further optimize the project schedule according to resource constraints, and finally guide the construction of the project. But the construction is complex, and the influencing factors are mostly concentrated in the whole construction project. [2] The construction planning problem gradually shows that the problem must be solved before the project can continue.

The traditional schedule management mode is complex and inefficient, which is prone to delay, waste of resources, economic loss and other issues. There are two main factors: the information and management mode. The smooth information transmission and the increasing scale of project construction will bring problems to the accuracy, timeliness and information sharing of project information. The main reason of this management mode is that it is difficult to adjust the plan and the overall management plan, and the content of the $2 \mathrm{D}$ chart is easy to conflict with the actual construction; there are many construction quantities, complex construction environment, many units, tight construction cycle, difficult project resource management, and difficult cost plan management.

\section{The AdVANTAgES OF BUILDING INFORMATION Modeling IN PROJeCT Schedule MANAGEMENT}

Compared with the traditional construction schedule control method, the application of building information

Higher education reform research project in 2018(2018YB004) 
modeling in the project has obvious advantages in the target construction schedule control, mainly including the following aspects [3].

\section{A. Relevance}

Different from traditional progress control methods, the construction schedule control method of building information modeling project is established on the basis of 3D model. The model can be used to simulate the project clearly and accurately according to the construction schedule, so as to realize the visualization of project progress. Through the process simulation, the corresponding relationship between the schedule and the actual schedule can be clearly understood, which effectively reduces the possible problems in the construction process of the schedule to ensure the accuracy and effectiveness of the project schedule

\section{B. Visualization}

Building information modeling will present public planning construction drawings with 3D form, which greatly convenient for work communication between technical personnel. Through the model, progress plan for each phase of the project can be made clear, so that every worker can have a clear understanding, greatly reducing the delay caused by professional problems.

\section{Simulation}

On the basis of the 3D model, we can decompose the project and get the model progress. Then in line with the $4 \mathrm{D}$ model, we could make the construction schedule of the whole project, release the simulation problems in advance, simulate the later construction process, and formulate the corresponding solutions. On this basis, we improve and optimize the original scheduling scheme, and carry out the simulation until the project simulation is successful. In the process of simulation, the theory of schedule cost dynamic management can be realized to improve the overall benefit of the project. In addition, in the process of simulation, conflict checking and conflict analysis can be carried out to effectively solve the existing wrong design and construction, find the problems in the design timely, and avoid late design changes due to design reasons. The simulation can greatly reduce the problems in the construction process, and effectively ensure the construction period and quality of the project.

\section{APPLICATION OF BUILDING INFORMATION MODELING IN PROJECT SCHEdUle MANAgEMENT}

\section{A. Management Form}

Progress simulation based on building information modeling is usually called 4D construction simulation, which is based on the premise of a high-precision 3D model. On the premise of having a high-precision 3D model, the model is imported into the construction simulation platform with relevant BOM, and building information modeling is combined traditional progress management with experience to realize the project progress information before construction. In order to achieve the real-time monitoring of the actual construction progress of the project, the actual engineering quantity simulation and dynamic control. This method can greatly adjust and optimize the disadvantages of traditional schedule management and improve the process of schedule management.

\section{B. Progress Information Control}

With the building information modeling platform as the core and the integrated model as the carrier, project progress supervision, quality and safety inspection cost and material management are carried out according to the process area. Simulate the working state of the physical field in any period of time, and display the model multiple times for viewing as needed; the planned progress is compared with the actual progress, and the project progress is visually viewed to provide data support for the project, achieve effective decision-making and fine management can reduce construction change, shorten construction period, control cost and improve quality. [4]Finally, the mobile terminal is used to track the prefabricated components, so that the construction parties can understand the current situation of the prefabricated components in real time, avoid the risk in advance, analyze the progress deviation at the PC end, automatically summarize and count the completed quantities at the web end, and complete the progress management of the whole process from processing to construction hoisting.

\section{Drawings Came}

Joint review of construction drawings is a check of drawings, traditional joint review of the regular occurrence of a variety of problems, problems after the solution cycle is longer, and not $100 \%$ to solve all the problems.

However, the joint review of drawings based on building information modeling is different from the traditional joint review of drawings. The traditional drawings are replaced by the intuitive 3D model. [5] This process is realized with the help of the feature of building information modeling visualization. In traditional construction drawing joint review, it is often necessary to combine multiple plans and clearly explain the problem. With the help of building information modeling, a 3D model can present the problem easily and intuitively. Not only that, after finding the problem, to coordinate the information sharing through the building information modeling platform, different design direction as well as between different professionals can be more direct rapid understand and deal with related issues, convenient and the collaboration between different departments, to avoid communication is not timely, information transmission lag between government departments or incorrect and the time limit for a project delay, resource waste and other issues. After the joint review, each major can modify the problems of the major in the model and synchronize the modifications to the building information modeling platform in real-time. All departments can directly see the latest modified model drawings for the first time.

\section{Construction of Rehearsal}

According to the flow area, the construction area is previewed, the masonry fine laying scheme is completed with one key, the structural column, horizontal beam, electromagnet pipeline, hole and other parts are automatically deducted, the T-type and L-type joints are laid, so as to accurately calculate the quantity and size of the masonry consumption, support the 
accurate supply and completion of the project, simulate the working state of the physical site at any time, and display the model as required, provide data support for the project, greatly reduce the temporary changes in the construction process, make the construction reasonable, greatly reduce the occurrence of accidents, reduce the waste of repeated pushing, greatly save time, manpower and material resources, shorten the construction period and reduce the cost.

\section{E. Real-time Progress Monitoring}

According to the planned construction flow section to divide the project and make a corresponding division in the model, and register the planned start time, planned end time, actual start time and actual end time in the building information modeling platform.

Building information modeling platform can compare actual progress and the plan of project schedule, in order to proceed with the project schedule real-time monitoring, when part of the construction progress lags behind, can be timely and intuitive will show the amount of lag to management personnel, and in a timely manner to the construction personnel and resources for proper adjustment, minimize impact.

\section{The Main Role of BuILding INFORMATION MODELING IN PROJECT ENGINEERING}

The reasonable application of building information modeling in project management can solve the problems and deficiencies in traditional work effectively. Through the construction of information modeling, we can integrate all the information of the whole life cycle data of the project, realize the effective sharing of information resources, improve the quality of work, integrate the application of building information modeling in project management, manage the information through dynamic database, accurately calculate the quantities according to the actual situation of the project, manage the budget according to the actual situation, and strengthen project cost control can reduce the adverse effects caused by human errors, make a scientific and reasonable resource management plan according to the system information, and improve the efficiency of resource utilization. The specific functions of building information modeling in the project are as follows:

1) Using the central database to realize information sharing and coordinate multiple disciplines. Building a central database based on the building information modeling can display the complex engineering information parameters. According to the actual situation of the project, the participants can obtain the information data parameters in time, and then reasonably participate in the project. Through the building information modeling, the hazards of the drawings in the construction can be effectively solved, the accuracy of the project cost can be improved, and the cost control can be strengthened, to achieve effective communication between the main parties, to lay the foundation for all work.

2) Project dynamic control and management is a project management model based on building information modeling, which can through the simulation management of construction process, the coordination of design can be improved, and the control and management of progress, quality and cost can be strengthened. [6] The project management mode can realize the dynamic management of the whole process of the project, lay the foundation for the construction and management of the project, ensure the orderly development of the project, and improve the economic benefits.

3) Project management based on building information modeling has the characteristics of self-improvement. [7] In the process of engineering construction, there is a problem that when a large number of engineering information projects are completed, the information in the previous stage will fail. In order to avoid the problems and deficiencies of the information system, it is necessary to deal with the existing problems in time. Based on the construction of building information modeling, and as the support of the dynamic management of project information, the continuous change and update of information data management can be realized, and the tracking and management of information in various stages can be realized, so as to improve the ability and level of project management.

\section{CONCLUSION}

There are many deficiencies in traditional schedule management, many technologies cannot adapt to the rapid development of various aspects, and the development of building information modeling can make up for any deficiencies of traditional schedule management. Advantages of building information modeling intuitively display various information, advance construction practice, real-time monitoring progress, etc., but in the industry, there is not much real use of building information modeling, so it is necessary to vigorously promote the popularization of building information modeling, with the popularization of building information modeling, the progress management of the project will be more scientific and reasonable.

\section{REFERENCES}

[1] Sun Ke. Research and application of BUILDING INFORMATION MODELING in project construction schedule management [D]. North China University of water resources and hydro power, 2018.(In Chinese)

[2] Cheng Yuting, Teng Li, Yu Gang, Hu Min. Study on construction schedule management of municipal engineering based on BUILDING INFORMATION MODELING [J]. Construction, 2016, 45(S1):768-771. (In Chinese)

[3] Yang Haolin. Research on construction project progress prediction and control based on BIM [D]. Xi'an: Chang'an University, 2018. (In Chinese)

[4] Zhang Lianying, Yu Fei. Construction of BUILDING INFORMATION MODELING based collaborative management system for construction engineering project schedule and cost [J]. Project management, 2014, 12(12):43-46. (In Chinese)

[5] Wu Xianguo, Qin Wenwei, Zhang Limao, Huang Yanhua. Research on project progress management and control based on BUILDING INFORMATION MODELING [J]. Construction economics, 2018, 39(10):59-63. (In Chinese)

[6] Xie Yong, Xie Tao, Qian Yousheng. Application research of BUILDING INFORMATION MODELING+ project management in engineering [J]. Construction .2018(14):154-157. (In Chinese)

[7] He Chenchen, Wang Xiaoming, Wu Jingxia, et al. Study on the progress control of construction projects based on BUILDING INFORMATION MODELING [J]. Construction economics, 2015, 6(2):33-35. (In Chinese) 